\title{
Hemostatic disorders of the menopausal period: the role of microRNA
}

\author{
Grzegorz Stachowiak, Agnieszka Zając, Marek Nowak, Tomasz Stetkiewicz, Jacek R. Wilczyński
}

Department of Gynecology and Gynecological Oncology, Polish Mother's Memorial Hospital - Research Institute, Lodz, Poland

\begin{abstract}
Adverse changes in hemostasis of menopausal women, observed e.g. in atherosclerotic or neoplastic cases, are of multicausal origin. It is believed that in the development and regulation of these processes, an important role is played by microRNA particles, which presence is ascertained in endothelial cells, atherosclerotic plaques and systemic circulation. Discovered for the first time over 20 years ago, up to now over two and a half thousand types of microRNA have been identified in the human body. MicroRNAs are single stranded RNA molecules of 20-24 nucleotides, encoded by the cell's genome and then transcribed by polymerase II. They regulate the expression of a large gene pool, approximately $30 \%$ of all genes, in the human body. MicroRNA molecules, like other bioactive molecules - RNA, protein - both play important roles in tumor invasion, metastasis, inflammation, coagulation, and regeneration. What is important, they can be detected not only in tissues (e.g. tumor tissues), but also in circulation (blood serum), where they are released. Accurate understanding of the role played by certain types of microRNA (e.g. miR-126, miR-17-92, miR-33, miR-613, miR-27a/b, miR-143, miR-335, miR-370, miR-122, miR-19b, miR-520, or miR-220) in hemostatic processes may allow in the future for their use not only as specific biomarkers of cardiovascular diseases but also as the target for innovative gene therapies.

Key words: microRNA, menopause, hemostasis, atherosclerosis, endothelium.
\end{abstract}

With age in women, but slightly later than in men, adverse effects are observed in hemostasis, which directly translates into an increased risk of diseases of the circulatory system. This risk primarily involves the increased incidence of thromboembolic events, both arterial and venous, being in many cases a result of the accumulation during menopause (understood broadly as pre-, peri- and postmenopause) of a number of cardiovascular risk factors. The list of known factors is particularly long in the case of the arterial system. Even the age of menopausal women itself is a risk factor for both arterial and venous diseases. Thus, it is not surprising that menopause is the period in which women often begin to develop diseases that are derived from adverse changes in hemostasis, including coronary heart disease, high blood pressure, or venous thromboembolism (VTE) [1-3].

Let us recall that among traditional risk factors for arterial thrombosis in women the following stand out: age $>50$ years, hypertension, abdominal obesity, hypercholesterolemia, impaired glucose tolerance and hyperinsulinemia, smoking, lack of physical activity. Whereas newer risk factors include: left ventricular hypertrophy, hypertriglyceridemia, elevated $L p(a)$, hyperhomocysteinemia, elevated serum concentrations of C-reactive protein (CRP), hyperfibrinogenemia. There are also the so-called hemostatic risk factors which, in addition to elevated levels of fibrinogen, include also increased activity of factors VII, VIII and von Willebrand factor (VWF), reduced fibrinolytic activity ( $\uparrow$ plasminogen activator inhibitor-1 [PAI-1], tissue plasminogen activator [t-PA] and t-PA/PAl-1 complexes), increased platelet activation and endothelial cell dysfunction (e.g. $\uparrow$ vascular cell adhesion molecule 1 [VCAM-1] or E-selectin) [4-7].

It is also emphasized that certain genetic polymorphisms of selected coagulation factors (e.g. factor $\mathrm{V}$ gene and the G20210A prothrombin gene), although not being independent risk factors for thrombosis, they increase this risk very much (e.g. the risk of myocardial infarction in smokers of tobacco, or in persons with metabolic risk factors) [8].

In recent times, more and more attention has been paid to the potential role of another genetic factor in the regulation of hemostasis, namely microRNA (miRNA). MicroRNAs are single stranded RNA molecules of 20-24 nucleotides, encoded by the cell's genome and then transcribed (just as mRNA) by polymerase II. The miRNA biosynthetic pathway is as follows: within the nucleus, from the genomic DNA (transcription with the use of RNA polymerase II), the longer thread of primary miRNA (pri-miRNA) is first formed, which subsequently under the influence of Drosha (complex of RNase III and Pasha protein, or DGCR8) is converted into pre-mature miRNA (pre-miRNA). Pre-miRNA is transferred from the 
nucleus to cytoplasm by the protein XPO5 (exportin-5), which is then converted to a mature miRNA, involving ribonuclease III - Dicer. MicroRNAs thus formed are fitted into the RISC complex (RNA-induced silencing complex), which post-transcriptionally inhibits the expression of target mRNA by binding to its 3' untranslated region (3'UTR) [9]. Binding of miRNA to the 3'UTR of specific RNA (complementary to its sequence) inhibits translation or promotes degradation of mRNA [10].

For the first time miRNA was discovered in 1993 in Caenorhabditis elegans (a small - about $1 \mathrm{~mm}$ in length - non-parasitic nematode, living in soils of the temperate climate) [11]. They were discovered then in humans, and for the next 20 years, over two and a half thousand various types of miRNA have been identified in the human body [12].

It has been shown that miRNAs are important regulators of many, both physiological and pathophysiological, processes in the human body. They are involved, inter alia, in the negative regulation of gene expression during development. They specifically block, in the mechanism described previously, translation of the mRNA, give them their specificity, and are also considered to be mediators of the interference mechanism of mRNA translation (RNA interference - RNAi). Their importance is based on the regulation of expression of a large gene pool (approximately $30 \%$ of all genes) in the human body. What is important, they can be detected not only in tissues (e.g. tumor tissues), but also in the circulation, blood serum, where they are released. MicroRNA molecules, like other bioactive molecules RNA, protein - both play important roles in tumor invasion, metastasis, inflammation, coagulation, and regeneration (using stem cells) [13].

In the context of menopause and the associated hemostatic disorders, first it is worth following the studies concerning the involvement of miRNAs in atherosclerotic processes and hemostatic disorders associated with neoplastic disease.

\section{Atherosclerotic disease}

Cardiovascular diseases (CVDs), being a derivative of the atherosclerotic process, are still not widely perceived as the greatest threat to the health and life of women. However, it is them, and not cancer (e.g. breast cancer), as is commonly believed, that is the major cause of mortality. According to the American Heart Association, CVDs arising from atherosclerosis are responsible for over $30 \%$ of all deaths in the U.S. [14].

Atherosclerosis is a slow process, which gives the first signs after many years of duration. A morphological sign of atherosclerosis is endothelial damage. A special role in the development of atherosclerotic lesions is attributed to inflammatory processes and disorders of lipoprotein metabolism. The fact that elevated blood cholesterol is a risk factor for heart attack, has been known since 1961 from reports of the Framingham Heart Study. In the development of atherogenic processes several steps are involved. They include: 1) endothelial cell dysfunction; 2) penetration of LDL into the subendothelial space and their modification; 3) migration of monocytes into the subendothelial layer, transforming them into foam cells and disintegration of the cells; 4) thrombogenesis and platelet release of growth factors and chemotactic substances; 5) middle layer $\rightarrow$ inner layer migration of myocytes in the vessel (with their subsequent growth); and 6) formation of intercellular connective tissue [15].

The view on the pathogenesis of atherosclerosis has evolved from assigning the leading role of lipids to recognize vascular inflammation as the main factor in the emergence and development of atherogenic changes. Any inflammatory response, also is in the vessel wall, occurs in several stages, including:

- margination, which is dependent only on the physical blood properties;

- rolling - a process involving some selectins (L-selectin, P-selectin, E-selectin);

- activation - where the main role is played by cytokines, in particular a large group known as chemokines, including platelet factor 4 (PF4), monocyte chemoattractant protein-1 (MCP-1), intercellular adhesion molecule 1 (ICAM-1);

- adhesion, dependent mainly on integrins and

- diapedesis - a process of leukocyte transition through the endothelial barrier and then through tissues into location of the antigen [16].

Modified in this way, endothelium begins to produce VCAM-1, by which monocytes and lymphocytes T are attached to the endothelial surface. Leukocyte migration across the endothelium is accomplished by monocyte chemoattractant protein-1 (MCP-1). Monocytes in the intima capture modified lipoprotein particles, transform into foam cells, then begin to produce cytokines and matrix metalloproteases (MMPs). Matrix metalloproteases are assigned a large role in plaque rupture, parietal thrombosis and the occurrence of acute cardiovascular events [17].

It is postulated that miRNA also participates in atherosclerotic processes. This applies in particular to endothelial cells (ECS) involved in most aspects of vascular biology ranging from inflammation, vasodilation to angiogenesis [18]. Endothelial cells dysfunction may result, among others, in the occurrence of hypertension, thrombosis and atherosclerosis [19]. Results of the last few years clearly show that, in the regulation of almost all EC functions, the key role is played by miRNAs. These include, among others, miR-126 and miR-17-92 [20].

MicroR-126 was one of the first miRNA detected in endothelium. It affects the control of vascular inflammation by inhibiting adhesion molecules VCAM-1 [21]. 
It plays also a central role in the regulation of angiogenic signaling and vascular integrity, directly inhibiting negative regulators of the VEGF signaling pathway, such as Sprouty-related protein 1 (SPRED) or phosphoinositol-3 kinase regulatory subunit 2 (PIK3R2/p85 $\beta$ ) [22]. It was also shown that miR-126, generated by ECS, is secreted into microparticles and apoptotic bodies, transferring a paracrine signal to target cells in the vessel. Apoptotic bodies created and released from Ecs during atherosclerotic processes, stimulate in the above mechanism the expression of CXCL12 - a gene located on chromosome 10, responsible for the production of stromal-derived factor-1 (SDF-1) protein, a cytokine which is highly chemotactic to lymphocytes, taking part among others in angiogenesis [23]. Administration of apoptotic bodies, or miR-126 results in inhibiting the atherosclerotic process (by promoting the incorporation of precursor cells, Sca-1+, to a vessel wall) [24]. Other known miRNAs affecting activation of ECs or participating in vascular inflammatory processes include miR-181b, miR-17-3, and miR-31 (expression of the last two is increased by TNF- $\alpha$, which, by influencing ICAM-1 and E-selectin, will lead to inhibition of the inflammatory response) [25].

An important role in atherogenesis is also played by a polycistronic cluster of several miRNA named miR-1792 , consisting of seven mature miRNA, namely miR-173p, miR-17-5p, miR-18a, miR19a, miR19b, miR-20a and miR-92a. This applies in particular to miR-92a, which regulates endothelial nitric oxide synthase (eNOS), an enzyme producing NO in ECs, so that vascular tone and angiogenesis is regulated. A molecular mechanism of regulating the expression of eNOS by miR-92a is complex. It has been shown that atheroprotective, laminar blood flow reduces the levels of miR-92a, which in turn inhibits Krüppel-like factor 2 (KLF2), a transcription factor regulating the expression of eNOS [26]. Krüppel-like factor 2 in turn increases intraepithelial expression of miR-143/145 which are secreted into microbubbles, and reaching vascular smooth muscle cells (VSCMs) act as an anti-atherogenic factor, inhibiting the expression of the E twenty-six (ETS) oncogene family - ELK1, Krüppel-like factor 4 (KLF4), calcium/calmodulin-dependent protein kinase II delta (CAMK2d), slingshot homolog 2 (SSH2), phosphatase actin regulator 4 (PHACTR4) and cofilin 1 (CFL1) [27].

Studies conducted in animal models indicate that miRNAs also have an impact on lipid metabolism. MicroRNA-33 (miR-33) is the first to demonstrate a relationship with high-density lipoprotein (HDL) metabolism, bile excretion, as well as with the so-called reverse cholesterol transport (RCT):

- miRNA-33 embedded within intron-2 of sterol-regulatory-element-binding protein-2 (SREBP-2), a transcription factor functioning as the main intracellular regulator of cholesterol homeostasis, which promotes gene expression for cholesterol biosynthesis and uptake, including e.g.: 1) HMG-CoA reductase (HMGCR) - an enzyme limiting cholesterol biosynthesis, 2) LDL receptor, or 3) proprotein convertase subtilisin/kexin type 9 (PCSK9) - an enzyme which, when attached to the LDL receptor, destroys it as well the LDL molecule bound to it. The clinical significance of the SREBP-2 path is by reducing serum LDL levels. It has been demonstrated that under physiological conditions the expression of miR-33 is regulated by intracellular cholesterol levels, and stimulated by statin treatment. Preliminary research also shows that miR-33 will suppress the expression of cholesterol transporter - ATP-binding cassette transporter 1 (ABCA-1); 3'UTR sequence of ABCA-1, which binds to miR-33, was then identified. ABCA-1 plays an essential role during the early stages of the biogenesis of HDL, mobilizing intracellular cholesterol into circulating ApoA-1. In mice with overexpressed miR-33, reduced hepatic levels of ABCA-1 were observed. More importantly, the suppression of hepatic miR-33 (using antisense nucleotides) leads to increased, hepatic levels of ABCA-1 (both mRNA and protein) as well as to elevated blood levels of HDL. These results suggest that persistent suppression of hepatic miR-33 can be effective in the treatment of patients with hypercholesterolemia in order to raise levels of anti-atherogenic HDL and thereby to reduce the risk of CVD $[28,29]$;

- miR-33 also controls the expression of sterol transporters secreted into bile, including ATP8B1 and $A B C B 11$. Severe functional mutations of the above factors result in familial progressive intrahepatic cholestasis - progressive familial intrahepatic cholestasis (PFIC) type 1 and 2. Whereas lighter mutations lead to mild, recurrent intrahepatic cholestasis - called benign recurrent intrahepatic cholestasis (BRIC), also type 1 and 2. In animal models, manipulations of hepatic miR-33 resulted in changes in the levels of bile secretion as well as changes in the total bile collection from the gallbladder. It was also shown that the use of statins in mice or Pagen diet (rich in fat, cholesterol and sodium chelates) resulted in the occurrence of the cholestatic phenotype. Importantly, this hepatic phenotype can be maintained using pre-treatment in the form of anti-miR-33 oligonucleotides, suggesting that miR-33 may mediate some statin effects in vivo [30, 31];

- cumulative data suggest that miR-33 stimulated physiologically by the reduction of sterols prevents their loss from inside the cell and controls the expression of their transporters (via ABCA-1 $\rightarrow \mathrm{HDL}$ and ATP8B1/ ABCB11 $\rightarrow$ bile). Both HDL and bile metabolism are important components of the previously mentioned RCT path, which mobilizes extrahepatic cholesterol to the liver in order to secret it into bile, and then 
expel in the feces. Although this route is a very inefficient method of removing sterols (more than 95\% of bile acids are reabsorbed in the small intestine and delivered back to the liver), this is the main mechanism for removal of cholesterol excess from the body - another known path is trans-intestinal cholesterol excretion (TICE). The RCT path is atheroprotective, facilitating the removal of sterols from macrophages within the atheroma. Available data support the hypothesis that suppression of miR-33 in patients with hypercholesterolemia may be cardioprotective in relation to CVDs [30, 32].

It has been shown in studies on animals (this time primates, not mice) that the use of oligonucleotides of anti-miR-33 for 16 weeks increased the plasma concentrations of HDL and decreased VLDL triglycerides [33]. In another study, four-week antisense therapy in LDLR -/mice, preceded by a 16-week period of a diet rich in fats and cholesterol, has caused the regression of atherosclerotic lesions [32]. However, this observation was not confirmed in the study where the above therapy (antimiR-33) was used in LDLR -/- mice over a period of 12 weeks [34]. The differences in the progression of atherosclerotic vascular lesions in cases of miR-33 deficiency, or treatment with anti-miR-33 are odd and may reflect a different expression of miR-33 in certain types of cells - hepatocytes, macrophages, or endothelial cells. One suspects that treatment with anti-miR-33 will be effective against cells where typically miR-33 is expressed.

It should be emphasized that primates, in contrast to rodents, also have a second gene of miR-33, derived from an intron of SREBP-1 - miR-33b. Hormonal factors, dietary or statin therapy differently regulate SREBP-1 and SREBP-2, which may be essential for understanding the role of miR-33a and miR-33b played in lipid homeostasis. The presence of miR-33b in primates has a beneficial effect on the metabolism of cholesterol and triglycerides and a positive response to treatment by antisense anti-miR-33 ( $\uparrow \mathrm{HDL}, \downarrow$ TG) [33].

Also other types of miRNA, including circulating miR-370 and miR-122 ( $\uparrow$ in hyperlipidemic patients, the positive correlation with coronary artery disease) and others, such as miR-613, miR-27a/b, miR-143, miR-335, miR-106, miR-125a, or miR-758 are related to the regulation of cholesterol/triglycerides metabolism [34, 35].

Whether any of the above miRNA will be used in the treatment of lipid metabolism disorders (including CVD) as anti-miR therapy, time will tell.

\section{Neoplasms}

Not since today it has been known that the neoplastic process affects hemostasis, including coagulation and fibrinolysis. Oncogenes (e.g. HER-2, RAS, EGFR, $M E T)$ presented by tumor cells not only alter the expression of pro-inflammatory agents, or angiogenic, but also affect coagulation, by changing e.g. the levels of tissue factor (TF) or PAI-1. This process is facilitated by the simultaneous loss of function of tumor suppressor genes (P53, PTEN) and changes in miRNA - for example, miR-19b or miR-520. Tumor cells themselves may start producing certain clotting factors - such as factor VII, or affect procoagulant properties of microparticles (MPs). Oncogenes may also deregulate functions of protease-activated receptors (PAR-1/2), which will affect the transmission of signals in the coagulation system. In addition, these processes involve microenvironment factors of the tumor (hypoxia), its response to stress factors (applied therapy), and mechanisms such as epithelial-to-mesenchymal transitions (EMT) and tumor initiating cell (TIC). The altered coagulation system will affect early (initiation of the process, angiogenesis), middle (growth, invasion) and late (metastasis, recurrence) stages of cancer's development [36].

Previously mentioned TF plays an important role not only in the clotting process, but also shows a number of other, both physiological and pathophysiological, functions in vascular wall hemostasis, angio- and tumorigenesis. Research in recent years has shown that miRNA, which plays a key role in post-transcriptional control of protein production by regulating the expression of one third of all human genes, also modulates the expression of biological functions of TF, both in physiological and pathophysiological processes, in different types of cancers [37].

It is postulated that the key component of the coagulation system - thrombin - is an enzyme that can be considered as a factor involved in carcinogenesis, promoting angiogenesis, stimulating platelet adhesion to endothelium as well as inducing tumor's growth and metastases. It is known that thrombin receptors (of the aforementioned PAR group) are present on the surface of many tumor cell lines. Thrombin itself has a direct effect on cancer cells by activating the cell cycle through down-regulation of p27 (Kip1) and induction of Skp2, cyclin D and A. MicroR-220, which inhibits p27 (Kip1) is up-regulated by thrombin. The inhibition of thrombin can lead to the arrest of tumor growth and may explain the inhibition of tumor growth and metastasis development with the use of anticoagulants (as observed in animal models), preferably affecting the survival rate in cancer patients treated with oral anticoagulants in several clinical studies [38].

\section{Disclosure}

Authors report no conflict of interest.

\section{References}

1. Stachowiak G, Stetkiewicz T. Choroba zakrzepowo-zatorowa w okresie menopauzalnym. Prz Menopauzalny 2010; 9: 212-216. 
2. Stachowiak G, Faflik U, Stetkiewicz T, Pertyński T. Choroby układu krążenia u kobiet - wpływ okresu menopauzy. Prz Menopauzalny 2006; 5: 382-387.

3. Stachowiak G, Faflik U, Zając A, et al. Nadciśnienie tętnicze u kobiet w okresie menopauzy. Prz Menopauzalny 2008; 7: 96-101.

4. Szostak WB, Cybulska B. Profilaktyka choroby niedokrwiennej serca w codziennej praktyce lekarskiej. Medycyna po Dyplomie 2000; wydanie specjalne: 61-66.

5. Kornacewicz-Jach Z, Podolec P, Kopeć G, et al. Konsensus Rady Redakcyjnej Polskiego Forum Profilaktyki Chorób Układu Krążenia dotyczący profilaktyki chorób układu krążenia u kobiet. Forum Profilaktyki 2006; 3: 1.

6. Ridker PM. Evaluating novel cardiovascular risk factors: can we bette predict heart attacks? Ann Intern Med 1999; 130: 933-937.

7. Bucciarelli P, Mannucci PM. The hemostatic system through aging and menopause. Climacteric 2009;12 Suppl 1: 47-51.

8. Lane DA, Grant PJ. Role of haemostatic gene polymorphism in venous and arterial thrombosis. Blood 2000; 95: 1517-1532.

9. Rottiers V, Näär AM. MicroRNAs in metabolism and metabolic disorders. Nat Rev Mol Cell Biol 2012; 13: 239-250.

10. Bartel DP. MicroRNAs: genomics, biogenesis, mechanism, and function. Cell 2004; 116: 281-297.

11. Wightman B, Ha I, Ruvkun G. Posttranscriptional regulation of the het erochronic gene lin-14 by lin-4 mediates temporal pattern formation in C. elegans. Cell 1993; 75: 855-862.

12. Horie T, Baba O, Kuwabara Y, et al. MicroRNAs and lipoprotein metabolism. J Atheroscler Thromb 2014; 21: 17-22.

13. Cho Y, Baldán A. Quest for new biomarkers in atherosclerosis. Mo Med 2013; 110: 325-330.

14. Lloyd-Jones D, Adams RJ, Brown TM, et al. Heart disease and stroke statistics - 2010 update: a report from the American Heart Association. Circulation 2010; 121: e46-e215.

15. Mijatovic V, van der Mooren MJ, Stehouwer CDA, et al. Postmenopausal hormone replacement, risk estimators for coronary artery disease and cardiovascular protection. Gynecol Endocrinol 1999; 13: 130-144.

16. Yu G, Rux AH, Ma P, et al. Endothelial expression of E-selectin is induced by the platelet-specific chemokine platelet factor 4 through LRP in an NF-kB-dependent manner. Blood 2005; 105: 3545-3551.

17. Libby P. Inflammation in atherogenesis. Nature 2002; 420: 868-874.

18. Pober JS, Sessa WC. Evolving functions o endothelial cells in inflammation. Nat Rev Immunol 2007; 7: 803-815.

19. Otsuka F, Finn AV, Yazdani SK, et al. The importance of the endothelium in atherothrombosis and coronary stenting. Nat Rev Cardiol 2012; 8 439-453.

20. Suarez Y, Fernandez-Hernando C, Yu J, et al. Dicer-dependent endotheial microRNAs are necessary for postnatal angiogenesis. Proc Natl Acad Sci U S A 2008; 105: 14082-14087.

21. Harris TA, Yamakuchi M, Ferlito $M$, et al. MicroRNA-126 regulates endothelial expression of vascular cell adhesion molecule 1. Proc Nat Acad Sci U S A 2008; 105: 1516-1521.
22. Fish JE, Santoro MM, Morton SU, et al. miR-126 regulates angiogenic signaling and vascular integrity. Dev Cell 2008; 2: 272-284.

23. Zernecke A, Bidzhekov K, Noels H, et al. Delivery of microR-NA-126 by apoptotic bodies induces CXCL12-dependent vascular protection. Sci Signal 2009; 2: ra81.

24. Zampetaki A, Kiechl S, Drozdov I, et al. Plasma microRNA profiling reveals loss of endothelial miR-126 and other microRNAs in type 2 diabetes. Circ Res 2010; 6: 810-817.

25. Suárez Y, Wang C, Manes TD, Pober JS. Cutting edge: TNF-induced microRNAs regulate TNF-induced expression of E-selectin and intercellula adhesion molecule-1 on human endothelial cells: feedback control of inflammation. J Immunol 2010; 184: 21-25.

26. $\mathrm{Wu} \mathrm{W}$, Xiao $\mathrm{H}$, Laguna-Fernandez $\mathrm{A}$, et al. Flow-dependent regulation of kruppel-like factor 2 is mediated by microRNA-92a. Circulation 2011; 124: 633-641.

27. Hergenreider E, Heydt S, Treguer K, et al. Atheroprotective communication between endothelial cells and smooth muscle cells through miRNAs. Nat Cell Biol 2012; 14: 249-256.

28. Najafi-Shoushtari SH, Kristo F, Li Y, et al. MicroRNA-33 and the SREBP host genes cooperate to control cholesterol homeostasis. Science 2010; 238: 1566-1569.

29. Marquart TJ, Allen RM, Ory DS, Baldan A. miR-33 links SREBP-2 induction to repression of sterol transporters. Proc Natl Acad Sci U S A 2010; 107: 12228-12232.

30. Allen RM, Marquart TJ, Albert CJ, et al. miR-33 controls the expression of biliary transporters, and mediates statin- and diet-induced hepatotoxicity. EMBO Mol Med 2012; 4: 882-895.

31. Morotti RA, Suchy FJ, Magid MS. Progressive familial intrahepatic cholestasis (PFIC) type 1, 2, and 3: a review of the liver pathology findings. Semin Liver Dis 2011; 31: 3-10.

32. Rayner KJ, Sheedy FJ, Esau CC, et al. Antagonism of miR-33 in mice promotes reverse cholesterol transport and regression of atherosclerosis. I Clin Invest 2011; 121: 2921-2931.

33. Rayner KJ, Esau CC, Hussain FN, et al. Inhibition of miR-33a/b in nonhuman primates raises plasma HDL and lowers VLDL triglycerides. Nature 2011; 478: 404-407.

34. Marquart TJ, Wu J, Lusis AJ, Baldan A. AntimiR-33 therapy does not alter the progression of atherosclerosis in low-density lipoprotein receptordeficient mice. Arterioscler Thromb Vasc Biol 2013; 33: 455-458.

35. Fernández-Hernando C. Emerging role of microRNAs in the regulation of lipid metabolism. Hepatology 2013; 57: 432-434.

36. Garnier D, Magnus N, D'Asti E, et al. Genetic pathways linking hemostasis and cancer. Thromb Res 2012; 129 (Suppl 1): S22-29.

37. Eisenreich A, Leppert U. The impact of microRNA on the regulation of tissue factor biology. Trends Cardiovasc Med 2014; 24: 128-132.

38. Green D, Karpatkin S. Role of thrombin as a tumor growth factor. Cell Cycle 2010; 9: 656-661. 